\title{
Lecture Format vs Inverted Classroom Format Results of a Study: First Year College Statistics
}

\author{
Manny Estabrooks \\ Red Deer College
}

\begin{abstract}
In today's educational environment, the internet represents a means for the wide dissemination of educational content that can be updated in minutes. It also presents a means for on line assessment with minimal or no human intervention. However, the degree to which participants achieve success in such an environment with facilities such as MOOC, is of great concern to the institutional officials involved.

The author suggests that a blending of on line content coupled with various strategies such as face to face interaction and intervention methods would help to alleviate some of the difficulties of strictly on line learning. Such strategies would tend to provide student engagement while at the same time enable the student to learn in a more focused manner with the instructor providing proper leaning support with a focus on the individual.

In this paper we present the results of a study comparing success rates in college level statistics for a lecture based format and one using the notions of the flipped classroom where the instructor in effect performing the role of a coach much as in sports.
\end{abstract}

\section{Introduction}

Digital technology has proved to be a great boon to individual expression and social awareness as well as providing a new era for accessing information unprecedented in history. Perhaps no sector of our socioeconomic society has benefited more than the education component. With its interactive capability and the delivery of educational content in a 24-7 format, it promises that education and learning can now be designed to fit into the learner's time and space constraints and thus ensure greater success in achieving one's educational goals.

Despite this, the author is of the opinion that extensive use of digital technology, and especially social media tends to promote a withdrawal of face to face $(\mathrm{F} 2 \mathrm{~F})$ engagement brought about in part by the uncertainties of $\mathrm{F} 2 \mathrm{~F}$ interactive communication. Furthermore, this leads to disengagement of the user, preferring to interact in a minimal manner and does affect the degree to which the learner can become engaged in the subject matter in a classroom situation.

This paper will focus on College level statistics and efforts by the author to address the very diverse needs of students in several sections of the course. Success in statistics requires a medium level of algebra and math skills accompanied by an appropriate level of reading and study skills. The lack of an appropriate level of skills in these areas, coupled with constraining factors such as extracurricular activities, outside work and addiction to social media all provide a complex interplay of variables which play significant roles in student success. Without appropriate schemes in place to address the issue of student success with these constraining factors in place, the instructor is faced with high dropout and failure rates in the class

This then begs the question as to how an instructor or professor is able to address the diverse needs of such students and at the same time ensuring greater student success without sacrificing course content and grade inflation.

\section{Initial Instructor Strategies}

In an effort to address these issues, the author has identified several strategies to meet the diverse learning needs of the student and provide greater opportunity for students to learn in his or her own time-space.

The author feels that traditional mathematics and statistics textbooks often have intimidating page layouts filled with formulas and very tight text layouts. Moreover the coverage is often so vast as to be very daunting to the beginner level student.

Presented with these constraints, the author has developed a 280 page "class workbook" intended to provide a focus of activity for the student on a day to day basis. The workbook features key aspects of the theory behind statistical methods as well as numerous word problems designed to engage the student in the class. The page layout of the book provides space for students to demonstrate through hand written techniques the methodology to solve various types of problems.

Furthermore, negotiations with a publisher resulted in the adoption of a customized text book with internet access to theory and word problems at a substantially reduced cost from the standard textbook. This enabled the student to carry out various on-line activities including study and guided inquiry in problem solving with on-line help as well as providing a means for self-testing. With appropriate on line feedback to the student, this scheme allowed the student to undertake a more or less independent approach to learning and allowing self-assessment to gauge one's skill level before the in class tests which were conducted on a quarterly basis. 
To further provide support to the learner, the author developed 39 on line videos of 10 to 15 minutes duration, corresponding to 35 class hours. Each video addressed a topic that was covered in each class and these same questions appeared in the workbook thus enabling the student to do the workbook problems at home using these on line videos. The videos were made available in a $24-7$ time frame in order that students are able to access the video content at any time.

Finally, a detailed weekly study guide specifying which videos to watch, workbook problems to be completed, and on-line assignments to be done with timelines involved. The study guide also provided an overview as well as the relevance of the material in relation to the overall course.

These strategies provided the background to compare the results of two distinct delivery methods, and determine their effectiveness as regards to student success in the statistics courses.

\section{Methodology for the Study}

In the winter term 2009, two sections of Statistics were identified to assess two teachinglearning methodologies. Group A consisted of one section conducted utilizing a more or less traditional approach with primary lecture techniques with PowerPoint presentations. The classroom workbook was used for a 10-15 minute problem solving session at the end of the class. Group B consisted of a second section of statistics conducted with the extensive use of videos, and very detailed weekly summaries of what sections of the textbook to read, problems to do and videos to watch. This class was conducted with a 15-20 minute presentation of key content material and problem solving techniques. Approximately 40 minutes of class time was devoted to group work with instructor availability for individual help. This time allowed for student engagement with a focus on problem solving and group work. This scheme is often referred to as the inverted classroom.

During the period January to February of 2009, both sections were conducted utilizing a traditional lecture format. The same tests and assignments were used as was the same PowerPoint presentations. Both sections wrote the same mid-term test in order to establish somewhat of a benchmark or level of achievement for each section.

At the February 20, 2009 winter break, the two methodologies outlined above were put into effect in two sections of the course. An attempt was made to reduce any instructor effect in these sections. In effect, Group A was conducted using the same traditional lecture based format as was used in the first part of the course and every effort was made to ensure that there was no difference in the presentation and classroom management method. However, the most significant difference in the approach to the teaching-learning process occurred in Group B.

The Group B methodology after the February 20, 2009 was dramatically different from that utilized in the January-February period. The instructor did spend considerable time emphasizing the on line videos and the need to view these videos prior to class. On two occasions, the instructor did present a video during the class time, it was noticeable that student attention span was of such short duration that some students became involved with his or her cell phones which were under the desk or in one's pocket. The connectedness of the student to the cell phone was extraordinary. In several cases, a student would pull out a chemistry or biology assignment to do during the viewing of the video. At the extreme three students fell asleep in the first eight minutes of the viewing. It seems obvious that such viewing during class time is not an acceptable practice.

The Group B methodology provided for considerable face to face interaction and enabled the instructor to focus on the individual student and his or her learning difficulties. In several cases the instructor did intervene in a student's life-space to suggest dropping a course or reducing the number of hours spent on outside work which would lead to greater chances of success in the course. This strategy proved to be very effective, but considerable effort was required on the part of the instructor to implement this strategy.

\section{Summary of the Results of the Study}

In April 2009 after classes finished the results were compiled for Group B and compared with the results for this same group at the beginning of the course. Figure 1 below illustrates a comparison between these two groups for the same time period.

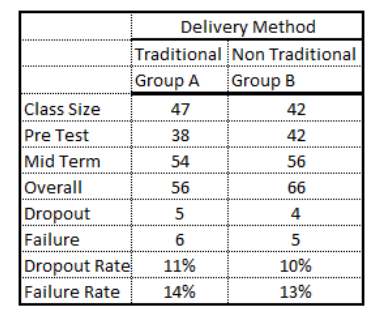

Figure 1. Comparison at the Beginning 
A glance at this figure shows that Group A performed much the same during the entire semester with marginal improvement during the semester. This is considered typical of lecture based delivery classes.

The figure above reveals that Group B experienced a significant change. At the mid-term, Group B mean was 56, standard deviation 21 with 3 cluster points of 27,47 and 77 . At the final overall for group B, the mean was 66 with a standard deviation 17 with a much more clustering of data in the 56-76 range. The clustering at $47 \mathrm{had}$ in effect changed having moved upward to the 57-70 range. Furthermore, there were more students performing at the A and B grade levels. Significant however was the fact that the bottom $25-30 \%$ did not appear to have moved and did not benefit from the classroom strategy.

It seems clear that the Group B benefited significantly from the classroom engagement and instructor attention during class. Moreover, students began to help each other in problem solving situations as well as making suggestions regarding which videos to view, which learning resources to use for study and so on. Overall, there appeared to be a greater sense of satisfaction with what was happening in the classroom. Indeed there were several occasions when a student would voice aloud that $\mathrm{s} /$ he was enjoying the classroom experiences.

On several occasions, a student would comment that a particular topic was not covered in class or was not available on the on-line videos. During several such exchanges, another student would provide comments to the effect that the material in question was covered in such and such a video as outlined on the weekly study guide. Exchanges such as this had the overall effect to suggest that it was the students responsibility to make the appropriate effort to follow the study guides and become more informed about the details of the course.

Worthy of note with regard to Group B approach related to student engagement. On several occasions the students were given a physical handout assignment and told that the assignment was due the next class at the beginning of that class. When students were given 20 minutes of class time to begin the assignment, they often worked in small groups of 2 and 3 students. At the end of the class, the instructor would often leave the class with virtually $100 \%$ of the class remaining in the class room to begin the assignment. Two days later, when the instructor went to the same class, most of the students had arrived early and had begun working on the assignment much as if they had never left the classroom of the previous class. The obvious question to be asked is why the students did not complete the assignment at home as was expected. With observations such as this, it became obvious that many students were not utilizing time away from class to spend any in study and homework relating to the course.

\section{Change in Instructor Role and Responsibilities}

The implementation of the flipped classroom results in a significant change in the role and behavior of the instructor. Most notable is the notion that the responsibility for learning in the course is more or less transferred from the instructor to the student. This observation alone suggests that the instructor spend much less time in the delivery of content since the content was available on the internet. This meant that there was much less anxiety and stress on the part of the instructor for the actual delivery of content by way of board work and PowerPoint presentations.

With the various instruments in place for the access of course content by the students in a 24-7 on line format, the instructor's role was reduced to one involving more or less a coaching role in the activities of the classroom. One could argue that this role involves expectations and behaviors that more befit an individual personality and as such, enables the instructor to begin to enjoy the benefits of person to person engagement together with the various other tools leading to greater student engagement in the classroom.

In this role of the instructor as coach, he or she is in effect relinquishing control of the actual learning in the class and begin to focus on activities and process that enhance individual outcomes. In this role, the instructor becomes more a "guide on the side" in contrast to a role such as "sage on the stage". The latter format is suggestive of a lecture based approach.

\section{Potential Factors in Student Success}

In an attempt to identify potential variables relating to student success or lack thereof, questionnaires were designed and administered with phone or personal interview follow-up. On the basis of the feedback obtained, the following "factors" were identified:

- Lack of an appropriate math \& study skills: In this study, there was no effort to place the student into a course where he or she would be most likely successful. Marks on a pretest for the statistics course ranged from a low of $28 \%$ to a high of $82 \%$ but this data was not used in any way other than to 
carry out statistical analysis at the end of the course;

- Number of courses enrolled: Typically a student carries a workload of 5 courses, some of which consist of $3 \mathrm{hrs}$ lecture with 2 or 3 hours lab or seminar. A particular program might involve 22 hours of class time, lab and seminar time;

- Outside work, often 16-24 hrs. per week: From feedback obtained from students $60 \%$ are involved with work not related to his or her academic studies. In one case, a student was taking 5 courses with 22 hours outside work. This often provides a significant factor in student success;

- Time spent on student activities \& sports: Students in the class are often involved in student committees or commit to overall college activities with corresponding degree of commitment;

- Social media, internet \& cell phone use: This phenomena alone can often be a significant factor in student success overall;

- Personal issues, family, relationships, money etc.: Often these variables impinge on the student in various ways in determining educational success. In this digital age, one can expect these types of variables to become more significant;

- Timing of the class, mid-day vs late day times: Although this may constitute a factor in success, it is felt that a student has a choice as to which class to attend and making a conscious decision regarding making a commitment to the course in question;

- Questionable Planning: Often a student will make an often unrealistic assessment of time commitments to a course. At the beginning of the year, a student may decide to take 5 courses and commit to 22 hours of outside work. When the academic year progresses, the work commitment will often remain the same while the number of hours of study time continually drops, in some cases to no hours at all;

Obviously there are many factors at play in the context of our study outlined above, and one could argue that these may be considered to be of a much less significance.

\section{Changing Environment}

For the past four years, the methodologies of Group B have been used in all class sections of statistics with similar success. Unfortunately, the success in recent years has been less dramatic but deemed to be successful none the less. The lessening of the degree of success of the methods outlined above is due in part to the changing dynamics surrounding the student. The following observations and speculations may be considered:

- Students less willing to assume responsibility for his/her learning in the course. This is evident when the student does not do the required homework in a timely manner;

- Greater feeling of entitlement \& expectations: It appears that and increasing number of students are of the opinion that "I paid for this course and it is your responsibility to get me through it". Similarly students are often not satisfied with a D in the course while performing at a 50\% level in the courses. In several situations, a student will challenge the grade to higher administration, simply because he or she needs a B to continue in a program;

- Greater connectedness to cell phones and social media to the extent that these devices with their rapid response and continuous engagement features tend to capture students attention subverting attempts to focus on one line of thought for a short period of time. It is common that a student will have the cell phone under his or her desk or concealed in a package, while his eyes constantly monitor the device for a response. The mere presence of a cell phone on another student's desk is often a distraction to other student in the class;

- Difficulty with comprehension and understanding word problems, especially those involving more than 30 to 40 words. This is often the result of extensive cell phone use. Text messages often consist of very short cryptic words and phrases that do not follow proper sentence. Furthermore, due to the limitation of letters in a text message, the student will often fail to appreciate the value of proper sentence structure. Thru time, the ability to write sentences following a particular structure is lost;

- Students constantly being bombarded with social responsibilities, demands of family and friends as well as various other obligations to the extent that he or she is unable to take the time to focus in a concentrated fashion on the subject matter at hand. This often results in the student not being connected to the subject matter of the course. An obvious result of this behaviour is that any sense of curiosity or speculations about the subject matter is lost or is often not there at all. This observation does suggest that the ready access to the internet may blunt inquisitiveness into subject matter to a significant degree;

- Students less willing to engage in face to face discussion or conversation, preferring to text message or email messages. When requesting a 
meeting with the student in instructor's office, a student would very often decline the request, preferring to conduct a meeting via email or text messaging. This behaviour extended to student's picking up assignments from the instructor's office. Typically $5 \%$ or under would drop by the instructor's office to pick up assignments when he or she was not in the class when assignments were handed back.

With variables such as these at play in the wider context of the classroom, it is felt that a radically new approach to teaching and learning strategies are necessary.

\section{Generalized Observations}

It is to be noted that this study does constitute a properly structured statistical experiment. The class sections do not constitute a random sample and furthermore, the same instructor conducted both sections involved in the study. This suggests that instructor behavior may be a factor in student success.

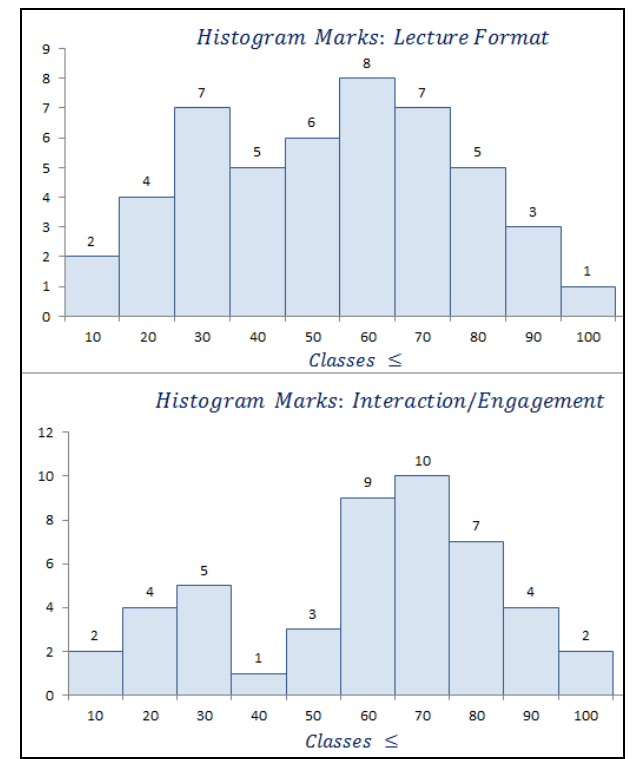

Figure 2. Histograms Lecture vs Inverted Classroom

However, in the years following the study described above, comparisons have been made between success rates in sections where the lecture method of delivery was used and other sections where the inverted classroom approach was used.

In courses where the lecture method is the primary delivery system is used and little or no classroom engagement strategies is involved, the student is more or less left on his or her own to put forth the effort necessary to succeed. In our study, a histogram similar to that illustrated in Figure 2 (top) may be expected. Students who are well prepared and are highly motivated might do very well in a class involving this scheme.

However, our study suggests that a course management scheme employing the features outlined above for Group B may be expected to follow a distribution or histogram as exhibited in Figure 2 (bottom).

This study suggests that greater involvement by the instructor in nontraditional classroom activities and course management schemes results in significantly greater student success. Students who do not demonstrate a significant commitment to the goals of the course are relegated to the bottom of the class, as Figure 2 illustrates.

The gap between those who pass and those who fail in such a scheme becomes more pronounced depending to a large degree on the role and behavior that he or she is willing to assume.

\section{Conclusions and Speculations}

It has been said that in the 1950's when televisions were placed in the classrooms of California schools, administrative officials suggested that they could eliminate $35 \%$ of the teachers. Obviously these officials thought that the students could learn from the television content simply by turning on the television in the class. Perhaps similar thoughts may have been expressed years earlier by placing a radio in the classroom and piping in educational content.

Most likely similar thoughts were expressed with the advent of mini computers, the Plato system of the late 1970's. Following these, we observed the advent of the microcomputers followed by the invention of the internet which allowed for the mass dissemination of educational content. The driving force behind this effort was simply to reduce costs and establish somewhat of a business model for education for the masses.

Unfortunately, times and circumstances change through the years as does the needs of the student. Here we are in the greatest technological age in the history of mankind and we are still trying to find the best way to address the problems associated with educating our populace. Often when we feel we have the solution to addressing these needs, the circumstances involving technology and society changes and our efforts often seem misplaced or diverted in some form or other. And so it seems to be the case that the technology will often divert the learner's attention away from learning a subject matter such as mathematics or statistics in a systematic and concentrated fashion and instead provide less technical material and those involving 
more entertainment and games. The result may be the loss of interest in the subject matter and loss of curiosity which is arguably the force for discovery and innovation.

And so it is felt that a new paradigm for education is necessary to address the learning needs of today's students. The lecture approach for a typical class of the past has failed us in today's educational circumstance. Perhaps a much more blended approach is necessary whereby we use some of the schemes of the past and combine these with a myriad of schemes that are intended to more attuned to the circumstances of a particular class, but more so attuned to the individual student's needs at the same time.

At the heart of any such scheme designed to meet these needs is the notion of student engagement. Engagement may take many forms in the classroom as well as outside the classroom. Such a strategy will most likely utilize the notion of the flipped classroom wherein the instructor may employ a wide variety of techniques to meet the needs of the class. Techniques such as group work both in the class as well as outside the classroom, problems solving sessions, project work, face to face discussion groups focusing on interactions are a just a few of the strategies that can form part of an overall approach to meeting these needs.

As we have attempted to outline in this paper, the role of the instructor is paramount in achieving success by way of increased success rates as well as increased student satisfaction. This role may be likened to that of a coach much like in sport. In such a role, the instructor may provide individual attention by way or encouragement and at times might involve intervention techniques designed to point the student in the direction of success in his or her own course as well as career path.

\section{References}

[1] Carr, Nicholas, The Shallows: What the internet is Doing to Our Brains, Norton \& Company, 2011 